\title{
Introduction: Methodical Aspects of Comparison
}

\author{
Oliver Freiberger
}

Department of Asian Studies, The University of Texas at Austin, 120 Inner Campus Dr Stop G9300, WCH 4.134, Austin, TX 78712-1251, USA; of@austin.utexas.edu

Received: 15 January 2018; Accepted: 2 March 2018; Published: 11 March 2018

Much ink has been spilled over the significance, the risks and benefits, and even the very possibility of comparison in the study of religion, but few scholars have reflected on how comparison actually works. Which methodical components should a comparative study include? Which problems does the comparativist encounter in deploying the comparative method? How is the design of the method related to the outcome of the study and to its value for the study of religion? The essays in this special issue begin to tackle these questions through analyses of concrete comparative studies.

The special issue has an unusual format which requires an explanation. The essays emerged from a panel on methodical aspects of comparison at the Annual Meeting of the American Academy of Religion in Atlanta in 2015. The panelists-who are also the authors of the present essays-were experienced comparativists in their respective fields: Francis X. Clooney (Harvard University), David M. Freidenreich (Colby College), Barbara A. Holdrege (University of California, Santa Barbara), and Jens Kreinath (Wichita State University). Kathryn McClymond (Georgia State University) served as a respondent at the panel session but contributed her own full essay here. These comparativists were invited to analyze and reflect upon their own comparative work along the lines of a basic methodological framework that I had outlined. Originally this was meant to be more of a specialists' roundtable, an opportunity for experienced comparativists to exchange ideas about the ways they employ the comparative method. Surprisingly, to me at least, the panel session was very well attended (with an audience of ca. 50 members), and afterwards some audience members requested that the contributions be published. Apparently this discussion struck a chord.

Thus we decided to stick to that format for the published version as well. The finalized essays, however, are more fleshed out and more sophisticated than the short contributions at the panel could be. My "input paper" outlines a methodological framework and terminology of comparison. ${ }^{1}$ The five authors then respond to the issues addressed in that framework each in their own way. Rather than reflecting upon comparison in a dry, theoretical manner, they discuss the methodical questions in the light of specific comparative studies that they have conducted. Engaging with the framework in this way produced rich essays, in which the authors highlight issues that are most relevant for them, criticize some components of the framework, and suggest new aspects and insights. Not only do they test the proposed terminology. They also address core issues that lie at the heart of the comparative method: How do we compare responsibly and productively? What can comparison achieve? What are the risks? And why is it important? Analyzing their own studies gave the authors the opportunity to systematically reflect upon the way they do comparison and to illustrate the methodological points with concrete examples. The proposed framework, on the other hand, ensures some coherence within this set of essays, since all authors engaged with the same initial parameters. This seems to be the first time that the method of comparison in the study of religion is put front and center in a collaborate discussion.

1 This framework will be included, in a revised and more elaborate form, in an upcoming book on the comparative method. 
Conflicts of Interest: The author declares no conflicts of interest.

(․) (1)

(C) 2018 by the author. Licensee MDPI, Basel, Switzerland. This article is an open access article distributed under the terms and conditions of the Creative Commons Attribution (CC BY) license (http://creativecommons.org/licenses/by/4.0/). 